
Not for reproduction, distribution or commercial use.

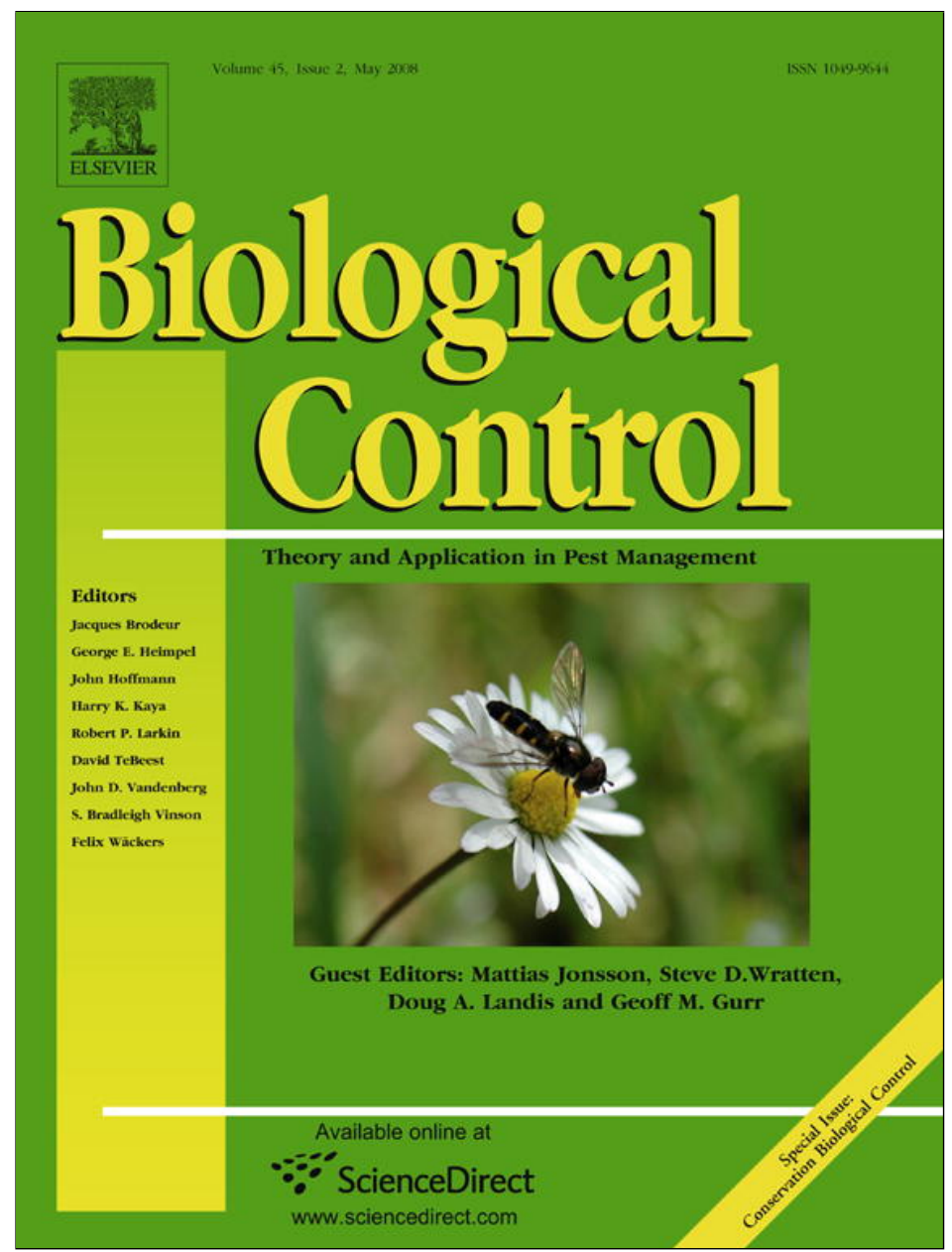

This article appeared in a journal published by Elsevier. The attached copy is furnished to the author for internal non-commercial research and education use, including for instruction at the authors institution and sharing with colleagues.

Other uses, including reproduction and distribution, or selling or licensing copies, or posting to personal, institutional or third party websites are prohibited.

In most cases authors are permitted to post their version of the article (e.g. in Word or Tex form) to their personal website or institutional repository. Authors requiring further information regarding Elsevier's archiving and manuscript policies are encouraged to visit:

http://www.elsevier.com/copyright 


\title{
Economics and adoption of conservation biological control
}

\author{
Ross Cullen $^{\text {a }}$, Keith D. Warner ${ }^{\mathrm{b}}$, Mattias Jonsson ${ }^{\mathrm{c}, *}$, Steve D. Wratten ${ }^{\mathrm{c}}$ \\ ${ }^{a}$ Commerce Division, P.O. Box 84, Lincoln University, Lincoln 7647, New Zealand \\ ${ }^{\mathrm{b}}$ Environmental Studies Institute, 874 Lafayette, Santa Clara University, CA 95050, USA \\ ${ }^{\mathrm{c}}$ National Centre for Advance Bio-Protection Technologies, P.O. Box 84, Lincoln University, Lincoln 7647, New Zealand
}

Received 28 August 2007; accepted 23 January 2008

Available online 31 January 2008

\begin{abstract}
Improving the conditions for natural enemies through conservation biological control (CBC) in agricultural landscapes has the potential to be economically beneficial, but economic assessments of $\mathrm{CBC}$ programs are rarely conducted. In this paper, we discuss how to complete an economic assessment of $\mathrm{CBC}$. We also ask what the research and development (R\&D) requirements are for CBC and the likelihood of that R\&D being funded. We examine the factors that may influence uptake of CBC amongst farmers and consider what policies or strategies might be introduced to increase the incentive to adopt $\mathrm{CBC}$. Relative advantage of $\mathrm{CBC}$ over other production systems, trialability (ease of informal field experimentation and learning before adoption) of $\mathrm{CBC}$ and the social dynamics of $\mathrm{CBC}$ development and extension are key factors influencing adoption. The most important social factors are the social learning processes to support agroecological practices, and the configuration of economic incentives to reward farmers for undertaking the transition to conservation biological control. By itself, neither social pressure to reduce insecticide use nor sophisticated scientific research guarantees expanded implementation of CBC.
\end{abstract}

(C) 2008 Elsevier Inc. All rights reserved.

Keywords: Cost benefit analysis; Ecological knowledge systems; Habitat management; Social learning

\section{Introduction}

Ecosystem services such as biological control are of great economic value for both individual landowners and society as a whole. In 1997, the world-wide economic value of natural biological control was estimated to be US\$417 billion/year (Costanza et al., 1997). More recently, Losey and Vaughan (2006) estimated the economic value for biological control of native herbivores in USA to be US\$4.49 billion/year. Both these estimates were probably very conservative. Due to more intensive land use leading to highly disturbed and simplified landscapes, biological control and other ecosystem services are declining (Naeem et al., 1994; Tilman et al., 2001). Improving the conditions for natural enemies through conservation biological control (CBC) in

\footnotetext{
* Corresponding author. Fax: +64 33253864.

E-mail address: jonssom2@lincoln.ac.nz (M. Jonsson).
}

such landscapes has the potential to be highly economically beneficial.

Several economic assessments of classical biological control programs have been carried out, indicating high benefit: cost ratio in some cases (see Menzler-Hokkanen, 2006 for a review). Well-known examples where the economic benefits of classical biological control have been very high are the control of the cottony cushion scale Icerya purchasi Maskell on citrus in California using the ladybird beetle Rodolia cardinalis (Mulsant) and the control of the cassava mealy bug Phenacoccus manihoti Mat.-Ferr. in Africa using the parasitoid Apoanagyris lopezi De Santis. In the latter case, Zeddies et al. (2001) estimated the benefit: cost ratio of this biological control program to be between 200 and 740 .

Very few economic analyses of costs and benefits of different $\mathrm{CBC}$ approaches are available. We conducted a search on ISI Web of Science in the Title/keywords/ abstract frame with the terms: ("conservation biological 
control" OR "habitat management") AND cost*, and ("conservation biological control" OR "habitat management") AND econom * (actual search terms in italics) and only found one study attempting an economic assessment of CBC. A similar search using Scopus did not uncover any further studies. Schmidt et al. (2007) studied the effect of living alfalfa (Medicago sativa L.) mulches on natural enemies and biological control of soybean aphids, Aphis glycines Matsumura, and found that this $\mathrm{CBC}$ measure decreased pest levels below the economic threshold. However, at the same time the alfalfa competed with the soybeans causing a yield reduction of $\approx 26 \%$, so it was concluded that this practice was not cost effective.

Fulfilling the potential of conservation biological control requires integration of the scientific discovery process with application of that knowledge by growers. This indicates the critical importance of understanding the social dynamics necessary to support ecologically-informed innovation in agriculture. The two most important dimensions of these dynamics are the social learning processes to support agroecological practices, and the configuration of economic, social or environmental incentives to 'reward' farmers for undertaking the transition to conservation biological control. By themselves, neither social pressure to reduce insecticide use nor sophisticated scientific research guarantees expanded implementation of CBC. Ultimately, farm managers must perceive ecologically based pest management knowledge to have economic advantages at acceptable levels of risk over the relatively simple (at least to use) agrochemical controls. Enhancing adoption of $\mathrm{CBC}$ requires understanding scientific, economic and social phenomena, and sharing that understanding through social networks (Warner, 2007a).

In this paper we explore how to complete an economic assessment of CBC. We ask what the research and development $(\mathrm{R} \& \mathrm{D})$ requirements are for $\mathrm{CBC}$ and the likelihood of that $R \& D$ being funded. We examine the factors that may influence uptake of CBC amongst farmers and consider what policies or strategies might be introduced to increase the incentive to adopt CBC.

\section{Economic evaluation of $\mathrm{CBC}$}

CBC can potentially contribute to farm profitability in several ways including: enhanced yield, (by reducing pests damage through $\mathrm{CBC}$ ); avoided cost (without yield loss); (examples include reduced need for insecticides because of the use of $\mathrm{CBC}$ ) and improved market-access (or maintained market access), which could occur for example when use of CBC results in reduced levels of residues in food and the food thereby meets market requirements. These market requirements are often described as non tariff barriers (NTB); i.e., higher price per unit of product. Consumers may be willing to pay a higher price for products which can demonstrate they have been produced using $\mathrm{CBC}$ and meet for example, maximum permitted residue requirements (Warner, 2007b). Outcomes from CBC are not assured and negative effects may occur in some cases (Landis et al., 2000). As well, introduction of CBC may compete with the crop and reduce yield, require initial investment by farmers and incur ongoing costs. Hence careful economic analysis is required to determine the economic merit of CBC.

Economists often evaluate projects or programs by way of cost benefit analysis (CBA). A widely used approach in CBA is to compare 'with' versus 'without' situations and we can use that approach to evaluate $\mathrm{CBC}$. Introduction and use of $\mathrm{CBC}$ will typically require additional expenditures by farmers, who hope those expenditures are at least matched by additional revenue or by reduction in some other expenditures. We can consider if the use of $\mathrm{CBC}$ is economically justified by comparing the expenditures and revenues for a farm 'with $\mathrm{CBC}$ ' to the expenditures and revenues they can expect 'without CBC.' Before we outline key steps in a $\mathrm{CBA}$ of $\mathrm{CBC}$, and recognizing that agriculture is a risky business with few certain outcomes, we can develop a summary of the potential biological effects of CBC. Fig. 1 illustrates possible population dynamics of a pest 'with' and 'without' CBC. The objective of $\mathrm{CBC}$ is to increase numbers and/or effectiveness of natural enemies of the pest 'with CBC' compared to 'without $\mathrm{CBC}$ ' as shown in part (a) of Fig. 1. The reduced numbers of pests
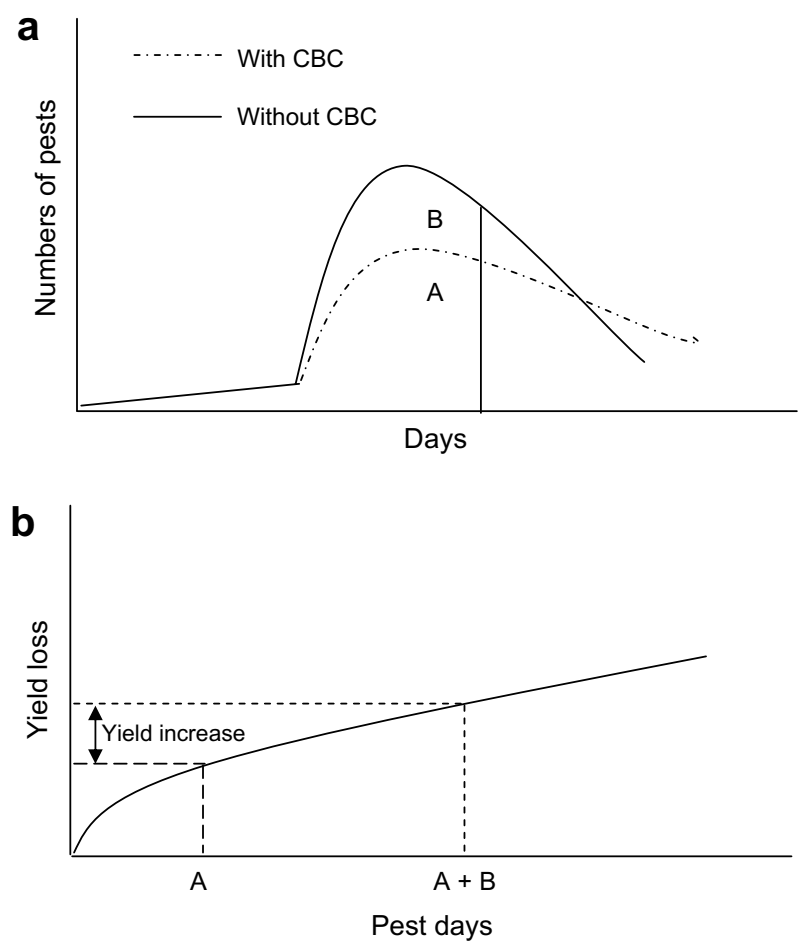

Fig. 1. Yield loss and effects of $\mathrm{CBC}$ on yield loss (adapted from Östman et al., 2003, Fig 1.) (a) Number of pest days with and without $C B C$ are the areas below the hatched $(\mathrm{A})$ and full lines $(\mathrm{B}+\mathrm{A})$, respectively. The area between the full and the hatched line (B) is the decrease in number of pest days. The vertical line indicates the number of pest days used in the example in Fig. 1b. (b) Yield loss as a function of the number of pest days. The increase in yield due to the $\mathrm{CBC}$ measure is the difference in yield loss without $\mathrm{CBC}(\mathrm{A}+\mathrm{B})$ and with $\mathrm{CBC}(\mathrm{A})$. 
in the 'with CBC' situation is expected to reduce the amount of crop yield lost through damage by the pest compared to the expected losses in 'without CBC' as shown in part (b) of Fig. 1.

As well as affecting population dynamics of the pests, $\mathrm{CBC}$ may influence the numbers of colonizing pests that are present before a farmer sows a crop. Farmers using $\mathrm{CBC}$ may maintain areas that are refuges for natural enemies of pests and the natural enemies result in lower numbers of colonizing pests being present before a crop is sown than occurs in a 'without CBC' regime. Fig. 2 illustrates possible development of pest numbers with and without $\mathrm{CBC}$, depending on the colonizing numbers of pests. Hence two types of effects may be attributable to $\mathrm{CBC}$ : differences in colonizing population of the pest $(w)$, and differences in growth rate of pest numbers $(\Delta r)$.

Landholders can decide how to respond to the numbers of pests present with and without $\mathrm{CBC}$ and these actions may impact on costs of production, yield, access to markets, product prices obtained. If pest levels are above some threshold level, landholders can decide to apply a pesticide or use some other management practice to reduce pest numbers, enhance yield, maintain access to a product market and increase prices for the product. These actions will typically incur some costs for landholders and they must weigh up the additional cost and expected payoff from the action. Introduction of $\mathrm{CBC}$ is likely to require investment of time by farmers learning about the innovation. They may need to trial $\mathrm{CBC}$ to determine its effectiveness and relative merit compared to current practices. If the $\mathrm{CBC}$ competes with the crop, yield may be reduced. Once farmers have decided to adopt the $\mathrm{CBC}$ innovation, there may be investments in new equipment, and additional expenditures on labor, machinery and materials.

We can now outline how economic evaluation of $\mathrm{CBC}$ can be completed that builds on the illustrative biological model and ideas about farming practices outlined above. Cost benefit analysis (CBA) of CBC can be completed to determine if a $\mathrm{CBC}$ introduction is warranted. A CBA can be completed by following a six step plan as follows: (1) select the 'perspective' used to complete the CBA-private, national, or global. This decision will determine whether 'local' or 'world' prices and costs are used in the CBA; (2) specify clearly the boundaries of the CBC 'project' to be evaluated, and the time period considered; (3) list the physical consequences of the CBC 'project'-inputs used, outputs produced; (4) estimate the monetary value of these inputs and outputs - the 'project' costs and benefits; (5) compare the project costs and benefits, discounting them as necessary; (6) summarize the results, and draw conclusions about the economic benefits of the $\mathrm{CBC}$ 'project.'

Simply stated, a CBA checks if the total benefits from an action exceed its total costs. This provides an efficiency test for a proposed action - it is warranted to use the resources if the benefits exceed costs. If a project's benefits and costs occur within one year, then the total annual benefits can be compared to the total annual costs. If the project has effects over more than one year, the net present value (NPV) of the project can be calculated.

$\mathrm{NPV}=\sum_{i=1}^{n}(B i-C i) /(1+d)^{i}$

where $B i$ are benefits, $C i$ are costs, $d$ is the discount rate, $i$ is year of the project.

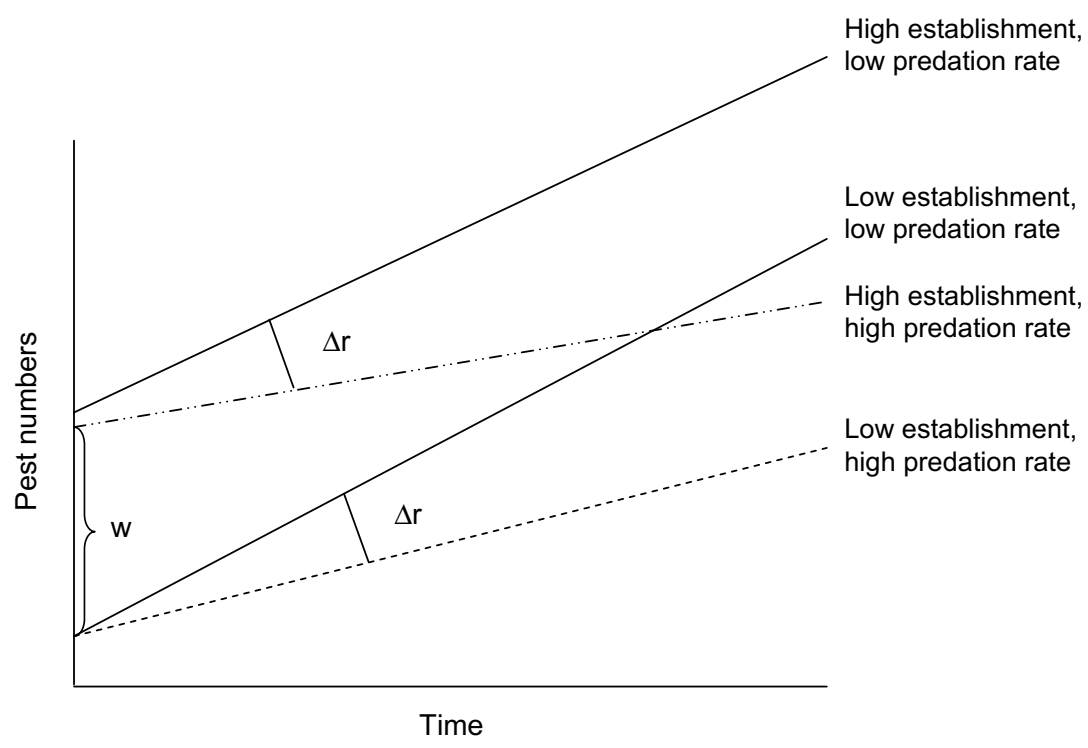

Fig. 2. Development of pest numbers with different rates of predation both during pest colonization ( $w$ ) and population growth $(\Delta r)$ (adapted from Östman et al., 2003, Fig. 3). $w$ is the difference in number of colonizing pests, due for example to differences in predation rate and $\Delta r$ is the effect of predation during the growth phase. Depending on when and how CBC measures are applied they can increase predation rates during both these phases. 
Economic theory provides guidance on what is to be counted as benefits and costs and how to measure their magnitudes (Hanley and Spash, 1993; Randall, 2002; Mishan and Quah, 2006). Market prices are useful places to start when estimating monetary values of benefits and costs, but subsidies, trade protection and other policies mean that agricultural prices in many countries are distorted from world prices and analysts may need to use world prices instead of local prices when completing a CBA. Zeddies et al. (2001) encounter this issue when evaluating $\mathrm{CBC}$ for cassava production in Africa and use world prices instead of local prices. Gutierrez et al. (1999) provide useful guidance on means of estimating benefits and costs of classical biological control and their comments can also be applied to evaluation of $\mathrm{CBC}$ projects. Benefits from classical BC comprise additional profits to farmers compared to profits without classical BC, as well as any other benefits. Costs of a classical $\mathrm{BC}$ project are any investments or expenditure needed to instigate and maintain the classical BC.

In addition to the direct benefits and costs to farmers, there may be external or social benefits and costs associated with the $\mathrm{CBC}$, and if their monetary values can be estimated, they can be included in the CBA. An example is $\mathrm{CBC}$ that reduces use of pesticides and has external benefits of fewer harmful health effects on workers or on nearby residents. Further examples include the value attached to improved water quality in a region, the value of wine produced without relying upon use of pesticides, and the value attached to increased biodiversity in agriculture after introduction of CBC. Economics has developed a range of approaches to deal with these types of situations. In some cases avoided cost approaches are used to provide a proxy for price. An example is the avoided cost of applying pesticide might be used as a proxy for the value attached to improved water quality in a region. Tait and Cullen (2006) provide examples of use of proxies to estimate costs of some external effects of agriculture.

A second approach is to complete careful analysis of markets to discern how much more is being paid for; e.g., wine produced using $\mathrm{CBC}$ rather than pesticides. A number of studies have been completed to find if consumers are willing to pay for environmentally safe production of timber products, fish, etc. (Ozanne et al., 1999; Vlosky et al., 1999). Jackson et al. (2007) studied the types of benefits that can be derived from agrobiodiversity. They report that despite considerable recent interest in the topic, more research is needed to determine the precise nature of the benefits and to enable economic evaluation of the magnitude of the benefits.

A third approach is to use non market valuation (NMV) techniques to estimate willingness to pay for items that are not 'sold' in markets. A wide range of NMV techniques have been developed to provide means to estimate monetary values for these non-marketed items (Hanley and Spash, 1993; Mishan and Quah, 2006). The most widely used NMV techniques are contingent valuation method and choice modeling. These are survey techniques that expose respondents either to a hypothetical market or ask them to choose amongst a small number of options that include specific attributes such as water and landscape quality. Analysts use these approaches to determine respondent's willingness to make tradeoffs. Such studies typically provide estimates of the value of a marginal or small change in a non traded item such as improved water quality, changed landscape, and production via environmentally friendly systems. Jetter and Paine (2004) use contingent valuation to estimate consumer's willingness to pay for biological control of pests in an urban landscape. They report Southern California urban residents' annual willingness to pay of US\$485 for the natural enemy option to control insect herbivores that damage trees and shrubs, compared to US\$131 for the bacterial spray option and US\$23 for the pesticide option. Randall (2002) surveyed the range of techniques available to estimate non market values associated with multifunctional agriculture such as changes in water quality or landscape.

In most cases when completing a CBA, researchers have to recognize that there are at least two types of uncertainties, technical uncertainty and value uncertainty (Jetter, 2005). Technical uncertainty arises when we are not certain about the biological or physical aspects of CBC such as its effectiveness in controlling the pest or any effects it may have on non-target species. Dealing with this type of uncertainty is often completed within a CBA by recognizing the probability of a range of outcomes occurring and estimating expected values of benefits and costs where Expected Benefits $=p i \times B i$ and Expected Costs $=p i \times C i$.

Because the probability of an outcome occurring ranges between 0.00 and 1.00 , expected values of benefits and expected values of costs are smaller magnitude than total benefits and total costs. CBC will pass the efficiency test if Expected Benefits $>$ Expected Costs.

Technical uncertainty over the effectiveness of CBC may be a deterrent to its adoption. Even if $\mathrm{CBC}$ has superior expected benefits to expected costs ratio than does conventional agriculture, the risk of severe failure to control a pest when using $\mathrm{CBC}$ and consequential economic impact may be unacceptable to some farmers (Warner, 2007a). Risk adverse farmers may prefer to continue with conventional agriculture if it has a lower probability of failure to suppress pests temporarily, even though they may become addicted to the 'ecological narcotic' of pesticides (DeBach, 1974).

Price uncertainty arises when we are not certain about price (or cost) levels. This uncertainty is likely to arise if introduction of the $\mathrm{CBC}$ will directly impact on product prices or input costs. This might occur if the $\mathrm{CBC}$ is large enough to shift supply level to a market and hence alter price, or if it is large enough to shift demand in a market for inputs such as pesticides and influence the market price. Jetter (2005) illustrates how changes in market demand and supply can be modeled to capture such effects when completing a CBA. A third possibility is where product price 
is dependent on cosmetic quality. Fenmore and Norton (1985) analyzed the impact off conservatory biological control on English dessert apple prices and noted that even a $1-2 \%$ shift from cosmetically perfect to damaged but usable fruit would pose a grave economic risk for growers. Perkins and Garcia (1999) comment that CBC may be best suited to crops that are not heavily dependent on cosmetic quality. CBA can be adapted to deal with price uncertainty by either sensitivity analysis (use of several prices or costs rather than just one), or by using an expected value approach that uses a probability distribution of prices.

Probabilities of outcomes occurring are often only weakly understood and analysts can use simple strategies to aid decision making in these situations. Jetter (2005) proposes that threshold probabilities at which the expected benefits equal the costs of CBC can be estimated as follows:

$E V_{\mathrm{b}}=P_{\mathrm{s}} \times B-C$

and by rearrangement $P_{\mathrm{s}}=-\frac{C}{B}$

$P_{\mathrm{s}}$ is the threshold probability, $C$ is costs and $B$ is benefits. Scientists familiar with $\mathrm{CBC}$ might consider based upon a qualitative assessment, how likely it is that the probability of success will exceed the threshold probability and thereby justify introduction of CBC.

\section{Adoption of innovations}

Adoption of $\mathrm{CBC}$ requires individual farmers to change their farming practices. Are $\mathrm{CBC}$ practices likely to be adopted? We have found few studies of adoption of $\mathrm{CBC}$ but adoption of conservation practices in agriculture has been extensively studied and we use that literature to suggest some key factors likely to play a role in adoption of CBC. Pannell et al. (2006) comment that adoption of innovations has three main elements: a process of learning by landholders, the relative advantage of the innovation over existing practices, and the trialability of the innovation where trialability refers to ease of test and learning before adoption. Trialability is influenced by divisibility of the innovation, observability of results, lags before results can be observed, complexity of an innovation, the cost of completing a trial, and the ability of the trial to indicate long run results (Pannell et al., 2006).

The learning process is an essential precursor to adoption and landholders need to become aware of the innovation, be able to understand it sufficiently to make a judgment on its likely value to them and be willing to adopt new practices. A range of landholder characteristics including age, education and goals has been found to partly explain variation in adoption rates between landholders (Pannell et al., 2006). Older landholders are less likely to adopt innovations that have long lags before payoff. Adoption of an innovation is often a social process rather than solely an individual decision; hence, a range of social and cultural factors may influence adoption. These often include strength of social networks, relationships between advocates of an innovation and landholders, and the level of extension and promotion activities for the innovation. Shadbolt (2005) in a study of attitudes towards CBC in Waipara, a wine producing region in New Zealand, found that female viticulturalists were twice as likely as were males to advocate biological control of pests.

Many studies have concluded that relative advantage is a key factor explaining adoption rates and the ultimate level of adoptions of innovations (Griliches, 1957; Rogers, 2003). Landholders are unlikely to adopt an innovation if it does not provide some relative advantage over existing practice. High establishment costs, long time scales, riskiness, complexity, and spillover of some benefits to other properties are all likely to hinder or reduce adoption of conservation innovations (Gutierrez et al., 1999; Perkins and Garcia, 1999). Pannell et al. (2006, p. 1409) comment that ... 'some conservation practices are relatively complex or the benefits and costs of some conservation practices are not clearly observable ...' Hence decision-making about these innovations by landholders may be impeded. Shadbolt (2005) found that potential for reduced costs, increased yield and marketing potential were all viewed by survey respondents as highly motivating factors for the use of CBC in vineyards.

Adoption of innovation often involves some risks for landholders as they have to depart from existing, known practices. One way for landholders to gauge the level of risk they face is to conduct a trial of the innovation. Innovations vary in their ease of testing and learning before adoption and this can influence the likelihood of adoption of innovations (Ohlmer et al., 1998). Shadbolt (2005) found that risk and labor costs involved in CBC were highly demotivating factors for growers. Their attitudes appear to have been influenced by their lack of knowledge and experience in biological control of pests. In the Waipara region, $\mathrm{CBC}$ trials have been conducted and their success may play a significant role encouraging more viticulturalists to adopt CBC.

\subsection{Public policy and $C B C$}

Economic and other incentives to adopt CBC innovations (cost reduction, yield increase, market access, higher prices, improved environmental outcomes) may not result in quick or widespread adoption. As noted above, this may be attributable to individual's characteristics, social and institutional factors, perceived lack of relative advantage of an innovation, and weak trialability of an innovation. A range of actions or public policies can be proposed to quicken adoption rates and target higher adoption level. Publicly funded extension activities are widely used to pursue those goals but their success is far from assured. Continued investment in extension is unlikely to overcome lack of relative advantage of an innovation. However, extension is likely to play a positive role in quickening the pace of adoption of innovations, 
particularly by raising awareness, and influencing landholders' perceptions about relative advantage especially if the innovation has low on farm trialability (Pannell et al., 2006).

In several parts of the world, rising public distaste for insecticide use has resulted in local community pressure to find non-polluting alternatives as well as public policy restricting insecticide use (Jetter and Paine, 2004). Although no studies have shown a direct causal relationship between these social factors, several studies have documented shifts in the farming community. These have shown that a significant minority of farmers in the developing world appear more favorably disposed toward pest management strategies that rely more on biological strategies (Röling and Wagemakers, 1998; Warner, 2007a,b). These general social pressures to find alternatives to hazardous insecticides have resulted in some groups of farmers perceiving this as an additional risk to be managed in their operations, resulting in collective initiatives to develop alternatives. The role of farmer risk perception is emerging as critical to understanding the obstacles to any biologically-based practice such as CBC (Warner, 2007a).

Where the economic incentives to individual landholders are insufficient to persuade them to adopt an innovation, perhaps in part due to a market failure of some type, there may be a case for financial incentives and market based instruments (MBI) to enhance adoption rate and level (Pascual and Perrings, 2007). MBI encompass a range of market like measures that can enhance economic returns to landholders and include auctions, subsidies, rebates, taxes, tradable rights, and labeling. Adoption of $\mathrm{CBC}$ in a wine growing region could be promoted by the group of wine growers introducing a label that highlights the use of $\mathrm{CBC}$ in the region, differentiating the wine and allowing producers to achieve higher prices than for unlabeled wine. Research has been completed in other sectors including forestry to determine how much consumers are willing to pay for differentiated (environmentally certified) products (Ozanne et al., 1999; Vlosky et al., 1999) and similar studies are needed for products produced with CBC.

\subsection{Ecological knowledge systems}

Farmers make decisions about their farming operations drawing from their knowledge base, or what rural sociologist Niels Röling calls an agricultural knowledge system: human understanding of how to organize the performance of crop and noncrop organisms plus agricultural technologies by using management techniques (Röling, 1992). In industrialized agriculture, the most important institutions shaping these knowledge systems have been public extension services. They have pursued their mission with a pedagogical strategy called the "transfer of technology." This has been a powerful model for the extension of industrial agriculture, for organizing the relationships between participants in agriculture (Röling, 1988; Röling and Jiggins, 1998). In it, science-based component technologies are developed for farmer "acquisition," and agricultural exten- sion is the delivery mechanism of those inventions. It assumes that scientists develop relevant knowledge in the laboratory which is then conveyed in the form of technologies through a 'pipeline' by extension agents to farmers, who then consume and apply this knowledge (Röling and Engel, 1990). This model has generally disregarded the potential of farmer innovation, and ignored examples of farmers' modifying practices and technologies in response to their local environment and farm-specific conditions.

As an agroecological pest management strategy (Altieri, 1989, 1995), CBC rests on an alternative epistemology or knowledge system (Kloppenburg, 1991). Farmers cannot simply replace pesticides with cover crops, companion plantings, and natural enemy nutrient supplements without some understanding of ecological relationships and principles. To contrast this approach with the knowledge base supporting conventional industrial agriculture, Röling and Jiggins (1998) propose the concept of an ecological knowledge system, one in which ecological strategies and tactics in farming are privileged, and agrochemical technologies are only used when ecological approaches are infeasible. Röling and Wagemakers (1998) provide examples from around the world of how scientists, extension agents and farmers have developed alternative approaches to generating ecologically informed knowledge such as CBC.

Röling and Jiggins (1998) see this as a shift toward adaptive management in agriculture. Their knowledge systems approach recognizes that fundamental change must occur off the farm as well as on it. They assert that there are five dimensions or scales of an ecological knowledge system:

1. Effective research on ecologically-sound practices.

2. Social learning.

3. Facilitation (extension).

4. Supportive institutions and networks (including research).

5. Conducive market and policy contexts.

These dimensions are interlocking pieces that are mutually interdependent. In the case of CBC, so far most attention has been paid to the development of ecologically sound practices through research (\#1 and \#4).

Röling and Jiggins (1998) argue that ecologically informed farm management cannot be successfully implemented without support from an ecological knowledge system. This depends upon an alternative extension pedagogy, one based on facilitating social learning, defined as participation by diverse stakeholders as a group in experiential research and knowledge exchange to enhance common resource protection (Woodhill and Röling, 1998; Warner, 2007a). Farmers need to take a more active role in educating themselves and their employees about agroecological processes such as the presence and performance of natural enemies. Extension agents will need to develop additional skills in facilitating social learning, and learn how to feel comfortable sharing control of the learning process. 
Farmer organizations, whether based on geography or commodity, and university researchers will also need to adopt new roles (Hassanein, 1999; Warner, 2007a).

This section draws from a qualitative study of the new social networks emerging in California to deploy agroecological practices such as $\mathrm{CBC}$ in conventional and organic agriculture. Its sources of information are semi-structured interviews with 126 growers, extension agents, scientists and grower organization staff; 13 focus groups with 84 network participants; and participant observation at 34 partnership-related meetings (Warner, 2007a). Studies of farmers developing knowledge of and confidence in ecologically informed farming systems such as CBC reveals a consistent pattern: few do it alone (Röling and Jiggins, 1998; Hassanein, 1999; Warner, 2007a). Farmers are more likely to learn about agroecological pest, nutrient, and soil management techniques from each other because other farmers have the greatest credibility. Farmers develop confidence in ecologically informed techniques such as CBC when they observe their fellow growers successfully negotiating the risks of new practices, adapt them to their specific farming system, and observe and improve the performance of the farming system with the help of other farmers trying out new techniques. This kind of learning requires a supportive network of other growers, not merely the transfer of technology. Farmers have to actively participate and take risks, in order to develop the skills to succeed in agroecological arthropod management. This requires an alternative set of social relationships among farmers, extension agents, and scientists: a supportive network or partnership (Hassanein, 1999; Warner, 2007a).

In California, agroecological partnerships have emerged as semi-privatized extension initiatives, informed by agroecological principles, as pollution prevention efforts. These partnerships define the most significant "sustainable agriculture" initiative to date in California, and deploy many CBC techniques (Warner, 2007a). CBC primarily relied upon non-crop plants. These partnerships placed a heavy emphasis on deploying cover crops between orchard or vineyard rows, and companion plantings in non-crop areas, such as along roads and creeks. Plants were selected to improve a range of different ecosystem services. In addition to providing floral nectar, beneficial habitat, and moisture for resident natural enemies, these plantings can also provide nutrients, improved tilth, orchard access during wet weather, and sediment trapping. There has been a significant investment among some conventional and organic farmers, especially perennial crop growers, to plant native plants in non-crop areas to foster biological control. Many organic strawberry and lettuce farmers on California's Central Coast invest $1-2 \%$ of their crop area in companion plantings to attract beneficial natural enemies (Colfer, 2004).

Over 500 California growers have participated in 32 distinct, multiple-year partnerships. The most successful partnership initiatives have taken place among growers of perennial crops. Many commodity-specific grower organizations have sponsored partnerships, and thus undertaken extension activities for the first time, motivated by fear of regulatory action against their growers. Many of these agroecological partnerships have been funded primarily by public environmental regulatory agencies because they perceive ecologically informed and participatory agricultural extension to be a more effective way to achieve their mission. In the Netherlands, many environmental cooperatives have developed along remarkably similar lines to California's agroecological partnerships. They began in large part as a response to increasing regulatory pressures; they emerge from previous cooperative networks; and they allow farmers to assert more control over their farming decisions (Renting and van der Ploeg, 2001). Other successful partnerships have been developed in the Waipara Valley and in Hawkes Bay in New Zealand where more than 40 winegrowers have adopted existing agroecological protocols and suggested new areas of research. This has led to extensive grower adoption of more sustainable practices which are complemented by eco-tourism through the establishment of 'biodiversity trails' in and around vineyards (www.waiparawine.co.nz).

The most successful agroecological partnerships have emerged in the context of prior cooperative efforts. They often build up prior social networks, often established to market a specific commodity, sometimes a geographically branded agricultural product. Partnerships develop in stages (Warner, 2007a). After partnership participants have developed and honed the most economically viable agroecological practices, many seek to add value to their crops, both to increase their income and to be able to afford deploying practices that are more expensive or involve more risk.

The California winegrape industry has invested time, money, and effort in agroecological partnerships, but also in enhancing the market value of their wine by branding it as "sustainable" (Warner, 2007b). The unusual relationship between the geography of premium winegrape production and the high prices of the premium wine market predict that this commodity would be the most likely to develop this strategy (Bisson et al., 2002). Premium winegrapes in California are grown in regions highly charged by environmental politics, and growers have found the value of cooperative initiatives to develop the knowledge system to reduce reliance on pesticides, in part by increasing reliance on conservation biological control. This is particularly true of organic production (Daane et al., 2005). More than any other group of U.S. farmers, California winegrape growers have developed what they describe as sustainable production techniques and are presenting their industry as sustainable (Anonymous, 2003; Dlott, 2004). These initiatives seek to increase the value and perceived quality of the wine (Warner, 2007b). Many regulatory agencies, environmental nongovernmental organizations, and agricultural organizations are developing third party certification schemes for engendering confidence among 
consumers that the price premium for "sustainably produced wine" is justified.

\section{CBC Research and development}

Introduction of $\mathrm{CBC}$ typically requires some research to demonstrate what works and what does not work. Research is costly and these costs must be met by some persons or organizations. There is extensive literature in economics, particularly agricultural economics, on the returns from research and development (R\&D) (Alston et al., 2000; Marshall and Brennan, 2001). Key questions asked in the returns to $R \& D$ literature include is there a tendency to under invest in agricultural $R \& D$ because knowledge has public good characteristics (Pardey et al., 2006)? Further key questions include who should, and who does fund agricultural R\&D? What impact does speed of adoption have on returns to R\&D? These questions are relevant for CBC which is likely to have strong public good features and hence is unlikely to be of interest to private sector funders (Gutierrez et al., 1999). In those circumstances funding is most likely to come from public sector organizations (such as USDA in the USA, CSIRO in Australia, FRST in New Zealand), and agricultural sector organizations or a combination of those two sources. As noted in the preceding section, agroecological partnerships are noticeable developments in the agricultural sectors of some countries and play key roles in development of new farming practices.

Agricultural R\&D often achieves real returns of 15-20 percent on the investments. Investments in classical biological control often provide very high returns on initial investment. Gutierrez et al. (1999) report benefit: cost ratios greater than 10.0 for 20 of 28 classical biological control projects studied. As noted in the preceding sections of this paper, there is a remarkable dearth of studies investigating the economic merit of $\mathrm{CBC}$. The almost complete lack of economic analysis of $\mathrm{CBC}$ means that there is also no information available on the returns to CBC R\&D and associated research questions.

\section{Concluding comments}

CBC can potentially provide a range of benefits to landholders including lower production costs, enhanced yield, maintained or enhanced market access, higher prices. But introduction of $\mathrm{CBC}$ also entails cost, can be risky and may have unintended consequences. Almost no research has been published that evaluates the economic benefits of CBC. Careful economic evaluation of $\mathrm{CBC}$ is needed to determine if it is delivering real economic benefits to individual farmers, regions or agricultural sectors. Fulfilling the potential of $\mathrm{CBC}$ requires economic studies that document its farming advantages (cost savings, enhanced yield, better market access) as well as the potential marketing advantages of value-added certification or labeling.
Achieving economic gains from $\mathrm{CBC}$ requires development of a new technology or farm practice, learning about them, making a decision to adopt the technology or practice, implementing them and incurring the necessary investments and operational costs. Farmers are more likely to take those latter steps if they have been involved in the development of the technology or practice, it has a clear relative advantage to farmers, and there are few barriers to adoption such as uncertainty, low trialability, unacceptable risk or long delay before payoff occurs. The importance of social networks in development, extension learning, and adoption of these innovations are key insights from research of these processes during the last 20 years. Future research needs include gathering more complete data on increased economic costs vs. benefits from adding value for CBC dependent products, incorporating farmer risk perception into decision making models, understanding the role that social networks play in shaping risk/cost benefit decision making, and documenting the impact that increased pricing for "sustainably produced" agricultural products could have on additional crops.

\section{Acknowledgments}

The authors acknowledge funding from the following sources: the Foundation for Research Science and Technology, via Research Contract LINX0303 (Ross Cullen and Steve Wratten), the National Science Foundation (award BCS-0302393; Keith Warner), the Biologically Integrated Farming Systems Work Group (Keith Warner), the UC Santa Cruz Department of Environmental Studies (Keith Warner), the California Department of Food and Agriculture (Keith Warner) and the Tertiary Education Commission, New Zealand, through the National Centre for Advanced Bio-Protection Technologies, Lincoln University, New Zealand (Mattias Jonsson and Steve Wratten).

\section{References}

Alston, J.M., Marra, M.C., Pardey, P.G., Wyatt, T.J., 2000. Research returns redux: a meta-analysis of returns from agricultural R\&D. Australian Journal of Agricultural and Resource Economics 44, 185215.

Altieri, M.A., 1989. Agroecology: a new research and development paradigm for world agriculture. Agriculture, Ecosystems, and Environment $27,37-46$

Altieri, M.A., 1995. Agroecology: The Science of Sustainable Agriculture. Westview Press, Boulder, CO.

Anonymous, 2003. Code of Sustainable Winegrowing Practices SelfAssessment Workbook. California Association of Winegrape Growers, and the Wine Institute, San Francisco, CA.

Bisson, L.F., Waterhouse, A.L., Ebeler, S.E., Walker, M.A., Lapsley, J.T., 2002. The present and future of the international wine industry. Nature 418, 696-699.

Colfer, R.G., 2004. Using habitat management to improve biological control on commercial organic farms in California. In: California Conference on Biological Control Proceedings, IV, pp. 55-60. 
Costanza, R., d'Arge, R., de Groot, R., Farber, S., Graso, M., Hannon, B., Limburg, K., Naeem, S., O’Neill, R.V., Paruelo, J., Raskin, R.G., Sutton, P., van den Belt, M., 1997. The value of the world's ecosystem services and natural capital. Nature 387, 253-260.

Daane, K.M., Smith, R.J., Klonsky, K.M., Bentley, W.J., 2005. Organic vineyard management in California, pp. $37 \mathrm{~N}-55 \mathrm{~N}$. organic-research.com.

DeBach, P., 1974. Biological Control by Natural Enemies. Cambridge University Press, London.

Dlott, J., 2004. California Wine Community Sustainability Report. California Sustainable Winegrowing Alliance, San Francisco, CA.

Fenmore, P.G., Norton, G.A., 1985. Problems of implementing improvements in pest control: a case study of applies in the UK. Crop Protection 4, 50-70.

Griliches, Z., 1957. Hybrid corn: an exploration of the economics of technological change. Econometrica 25, 501-523.

Gutierrez, A.P., Caltagirone, L.E., Meikle, W., 1999. Evaluation of results. Economics of biological control. In: Bellows, T.S., Fisher, T.W. (Eds.), Handbook of Biological Control. Academic Press, San Diego, CA, pp. 243-252.

Hanley, N., Spash, C.L., 1993. Cost-Benefit Analysis and the Environment. Edward Elgar, Aldershot, UK.

Hassanein, N., 1999. Changing the Way America Farms: Knowledge and Community in the Sustainable Agriculture Movement. University of Nebraska Press, Lincoln, NE.

Jackson, L.E., Pascual, U., Hodgkin, T., 2007. Utilizing and conserving biodiversity in agricultural landscapes. Agriculture, Ecosystems and Ecology 121, 196-210.

Jetter, K., 2005. Economic framework for decision making in biological control. Biological Control 35, 348-357.

Jetter, K., Paine, T.D., 2004. Consumer preferences and willingness to pay for biological control in the urban landscape. Biological Control 30, $312-322$.

Kloppenburg, J.R., 1991. Social theory and the de/reconstruction of agricultural science: local knowledge for an alternative agriculture. Rural Sociology 56, 519-548.

Landis, D.A., Wratten, S.D., Gurr, G.M., 2000. Habitat management to conserve natural enemies of arthropod pests in agriculture. Annual Review of Entomology 45, 175-201.

Losey, J.E., Vaughan, M., 2006. The economic value of ecological services provided by insects. BioScience 4, 311-323.

Marshall, G.R., Brennan, J.P., 2001. Issues in benefit-cost analyses of agricultural research projects. Australian Journal of Agricultural and Resource Economics 45, 195-214.

Menzler-Hokkanen, I., 2006. Socioeconomic significance of biological control. In: Eilenberg, J., Hokkanen, H.M.T. (Eds.), An Ecological and Societal Approach to Biological Control. Springer, Dordrecht, The Netherlands, pp. 13-25.

Mishan, E.J., Quah, E., 2006. Cost-Benefit Analysis, fifth ed. Routledge, UK.

Naeem, S., Thompson, L.J., Lawler, S.P., Lawton, J.H., Woodfin, R.M., 1994. Declining biodiversity can alter the performance of ecosystems. Nature 368, 734-737.

Ohlmer, B., Olson, K., Brehmer, B., 1998. Understanding farmers' decision making processes and improving managerial assistance. Journal of Agricultural Economics 18, 273-290.

Östman, Ö., Ekbom, B., Bengtsson, J., 2003. Yield increase attributable to aphid predation by ground-living polyphagous natural enemies in spring barley in Sweden. Ecological Economics 45, 149-158.

Ozanne, L.K., Bigsby, H., Vlosky, R.P., 1999. Environmental certification of forest products: the New Zealand customer perspective. New Zealand Journal of Forestry 43, 17-23.

Pannell, D.J., Marshall, G.R., Barr, N., Curtis, A., Vanclay, F., Wilkinson, R., 2006. Understanding and promoting adoption of conservation practices by rural landholders. Australian Journal of Experimental Agriculture 46, 1407-1424.

Pardey, P.G., Alston, J.M., Piggott, R.R., 2006. Agricultural R\&D in the Developing World: Too Little, Too Late? International Food Policy Research Institute (IFPRI), Washington, DC.
Pascual, U., Perrings, C., 2007. Developing incentives and economic instruments for in situ biodiversity conservation in agricultural landscapes. Agriculture Ecosystems and Environment 121, 256268.

Perkins, J.H., Garcia, R., 1999. Social and economic factors affecting research and implementation of biological control. In: Bellows, T.S., Fisher, T.W. (Eds.), Handbook of Biological Control. Academic Press, San Diego, CA, pp. 963-1009.

Randall, A., 2002. Valuing the outputs of multifunctional agriculture. European Review of Agricultural Economics 29, 289-307.

Renting, H., Van der Ploeg, J.D., 2001. Reconnecting nature, farming and society: environmental cooperatives in the Netherlands as institutional arrangements for creating coherence. Journal of Environmental Policy and Planning 3, 85-101.

Rogers, E.M., 2003. Diffusion of innovations, fifth ed. Free Press, New York.

Röling, N., 1988. Extension Science: Information Systems in Agricultural Development. Cambridge University Press, New York.

Röling, N., 1992. The emergence of knowledge systems thinking: a changing perception of relationships among innovation, knowledge process and configuration. Knowledge and Policy: The International Journal of Knowledge Transfer 5, 42-64.

Röling, N., Engel, P., 1990. The development of the concept of agricultural knowledge information systems (AKIS): implications for extension. In: Rivera, W.M., Gustafson, D.J. (Eds.), Agricultural Extension: Worldwide Institutional Evolution and Forces for Change. Elsevier Science, Publishing Company, New York, pp. 125-138.

Röling, N., Jiggins, J., 1998. The ecological knowledge system. In: Röling, N.G., Wagemakers, M.A.E. (Eds.), Facilitating Sustainable Agriculture. Cambridge University Press, New York, pp. 283-309.

Röling, N., Wagemakers, A. (Eds.), 1998. Facilitating Sustainable Agriculture: Participatory Learning and Adaptive Management in Times of Environmental Uncertainty. Cambridge University Press, Cambridge.

Schmidt, N.P., O'Neal, M.E., Singer, J.W., 2007. Alfalfa living mulch advances biological control of soybean aphid. Environmental Entomology $36,416-424$.

Shadbolt, A.A.K., 2005. 'Greening Waipara': viticulturalist's attitudes and practices associated with a region-wide ecological restoration scheme. BSc (Hons) dissertation, Lincoln University, Canterbury, New Zealand.

Tait, P., Cullen, R., 2006. Some external costs of dairy farming in Canterbury. In: 50th AARES Annual Conference, Manly, Australia. http://www.aares.info/aares_conference_2006.

Tilman, D., Fargione, J., Wolff, B., D'Antonio, C., Dobson, A., Howarth, R., Schindler, D., Schlesinger, W.H., Simberloff, D., Swackhamer, D., 2001. Forecasting agriculturally driven global environmental change. Science 292, 281-284.

Vlosky, R., Ozanne, L.K., Fontenot, R.J., 1999. A model of U.S consumer willingness to pay for environmentally certified products. Journal of Consumer Marketing 16, 122-140.

Warner, K.D., 2007a. Agroecology in Action: Extending Alternative Agriculture through Social Networks. MIT Press, Cambridge.

Warner, K.D., 2007b. The quality of sustainability: agroecological partnerships and the geographic branding of California winegrapes. Journal of Rural Studies 23, 142-155.

Woodhill, J., Röling, N., 1998. The second wing of the eagle: the human dimension in learning our way to more sustainable futures. In: Röling, N.G., Wagemakers, M.A.E. (Eds.), Facilitating Sustainable Agriculture: Participatory Learning and Adaptive Management in Times of Environmental Uncertainty. Cambridge University Press, Cambridge, pp. 46-71.

Zeddies, J., Schaab, R.P., Neuenschwander, P., Herren, H.R., 2001. Economics of biological control of cassava mealybug in Africa. Agricultural Economics 24, 209-219. 